\title{
Environmental and Social Risks and Solution Criteria in Offshore Aquaculture Systems
}

\author{
Birol BAKI ${ }^{*}$, Dilara Kaya ÖZTÜRK ${ }^{* *}$ \\ * Sinop University, Faculty of Fisheries, Department of Aquaculture, Sinop, \\ bbaki@sinop.edu.tr \\ ${ }^{* *}$ Sinop University, Faculty of Fisheries, Department of Aquaculture, Sinop, \\ dilara.kaya55@gmail.com
}

\begin{abstract}
Aquaculture is a sector that involves agricultural activities aiming to meet the increasing animal food demand, contribute to balanced and healthy diet and reduce the hunting pressure on natural fish stocks. In aquaculture activities in sea, producers who are aware of the major role of obtaining an ecological balance in production regard coast utilization and environmental management as a part of production. Therefore, determination of environmental factors in production activities is highly important for sustainable aquaculture. The present study aims to determine the environmental risks and solution criteria in offshore aquaculture systems in Turkish seas. Environmental and social risks in production are collected under the main headings comprising nutrient and waste load in water, feeding, overuse of antibiotics and chemicals, fish escape, diseases, working conditions and common areas; solution criteria are collected under the main headings comprising ecosystem, water management, feed properties, legal procedure, chemical use, field management and occupational health and safety.
\end{abstract}

Keywords: Offshore, Aquaculture, Environmental Risks, Social Risks, Solution Criteria

\section{INTRODUCTION}

The disproportionately slow increase in food sources, in spite of the rapidly increasing world population is predicted to become a problem. The factors such as decreasing farm lands, changes in climate and water conditions and the decreasing productivity hinder agricultural production. Water products, as protein sources of animal origin, has an absolute importance in human nutrition and food supply. Aquaculture is one of the sectors of agricultural activities that aims to meet the increasing animal food demand, contribute to balanced and healthy diet and reduce the hunting pressure on natural fish stocks.

In recent years, Turkey has become a prominent country in Europe with its high yield in the aquaculture sector, which started in the mid1980 s and grew very rapidly. Approximately $18 \%$ of the Turkish aquaculture enterprises are made up of marine enterprises, and sea bream (Sparus aurata) and sea bass (Dicentrarchus labrax) production constitute most of the production made in the seas (91.5\%) [1]. Approximately $18.5 \%$ of enterprises (enterprises up to 1000 ton-capacity) and $63.9 \%$ of the total production capacity have to prepare production impact reports during project preparation and carry out monitoring activities during the production period in accordance with Annex-1 of the Regulation on Environmental Impact Assessment of the Ministry of Environment and
Urbanization [2].

In aquaculture activities in sea, producers who are aware of the major role of obtaining an ecological balance in production regard coast utilization and environmental management as a part of production. Therefore, determination of the natural properties of production areas and their environmental impacts are highly important for sustainable aquaculture.

The present study aims to determine the environmental risks and solution criteria in offshore aquaculture systems in Turkish seas. Environmental and social risks in production are collected under the main headings comprising nutrient and waste load in water, feeding, overuse of antibiotics and chemicals, fish escape, diseases, working conditions and common areas; solution criteria are collected under the main headings comprising ecosystem, water management, feed properties, legal procedure, chemical use, field management and occupational health and safety.

\section{ENVIRONMENTAL and SOCIAL RISKS}

Nutrient and Waste Load in Water

The aquaculture sector faces criticism from environmentalist groups because of the nutrient and waste load it releases into the environment. However, the clean water concept in the sector is not only necessary for production but also required for 
its release into the environment and for protection of the cultured environment. Incorrect feeding methods, intensive stocking, excessive nitrogen and phosphorus in the environment cause excessively increased algae production, decreasing oxygen amounts and eutrophication [3]. This, in turn, reduces the oxygen amount required in the production area and threatens the life in waters.

Phosphorus, nitrogen, organic substances and suspended solid matters in water are among the factors causing pollution in fish farms [4]. It was reported that the eutrophication due to aquaculture caused certain changes in the water quality of closed basins and usually caused decrease in light transmittance and increase in nutrients, electrical conductivity and chlorophyll-a amounts [5]. Although the amount and quality of the waste waters of the sector changes depending on the location and the type of the system, in intensive productions, $30 \%$ of the waste water is released into the environment as unconsumed feed and $30 \%$ of the waste water is released into the environment as feces [6].

\section{Feeding}

Feeds consist of organic and inorganic substances and water. Aquaculture feeds usually contain $0.9-1.5 \%$ phosphorus and 7-8\% nitrogen. Although nitrogen intake through feeds depends on the species, it usually is around $20-30 \%$ and the remaining $70-80 \%$ is released back into the water.

In fish production, the pollution due to feeds depends on the physical and chemical properties of the feeds and the feeding method. The feeds produced with the extruder technology have more water resistance and these feeds are more resistant to disintegration-induced breaking. Thanks to the technologies used in feed production, feeds at desired densities can be produced and feed losses are prevented by controlling the sinking rate of the feeds. Applying the vacuum lubrication method instead of the impregnation method during the external lubrication process in feed production reduces oil leakage into the water environments.

Selecting raw materials with higher digestibility and lower cellulose content in feed production reduces feces release by increasing feed digestion. For the feeds used in feed nutrition to cause less pollution, the required nitrogenphosphorus balance must be provided depending on the fish species and age. In aquaculture, by meeting the optimum protein and energy requirements of fish, waste feeds and nutrient losses can be prevented [7]. Furthermore, eutrophication can be prevented with polyculture applications (sea fish and crustaceans) [4].

\section{Overuse of Antibiotics and Chemicals}

Most of the chemicals used in aquaculture are used to control fish diseases, improve the water quality criteria and decrease biological pollution. Antifouling chemicals, disinfectants, algicides, herbicides, pesticides, parasiticides and bactericides are the main chemicals used in aquaculture. In their study carried out with antibiotics, Ferreirea et al. (2007) [8] reported that high oxytetracycline and florfenicol concentrations inhibited the growth of Tetraselmic chuii.

In open cage systems, pesticides are used to avoid sea lice. In some pesticide applications, the resistance of lice to the drugs increased and their uses had dropped [9]. Deltamethrin, which is used as an active agent in drugs used in the control of sea lice, can remain suspended in the sea column for weeks. Moreover, these applications are reported to also cause deaths in non-target species (Pandalus plantyceros) [10].

Biological pollution is a challenging and expensive production problem for the aquaculture sector. Antifoulings are chemicals used to reduce the biological pollution in aquaculture equipment. Copper is used as an active agent for most antifouling chemicals and as well as being highly harmful to the environment, it is reported to have toxic effects on non-target species. It was reported that antifouling substances had negative effects on oyster growth and reproduction [11]; they damaged fish gills [12]; they inhibited phytoplankton growth $[13,14]$. Moreover, it should also be considered that antifouling substances accumulate at the sea bottom. For example, copper was determined in a sediment collected from a location that was $300 \mathrm{~m}$ away from a salmon farm in Scotland [15].

\section{Fish Escape}

Fish can escape from production areas because of the factors such as human error, mechanical failures or predator animals. When cultured species genetic properties of which is different from the natural stock are bred, as a result of high growth and low hunting activities, may have low adaptation to the natural life or, on the contrary, can become dominant in the natural environment and hybridize with the natural stock and cause the emergence of new stocks that have low adaptation to the ecosystem. The escape of cultured species has the potential to cause problems such as settling in the natural environments as invasive species, commensalism and disease spreading and especially the deterioration of the gene pool. Kastanevakis et al. (2013) [16], reported that aquaculture was responsible for $16.4 \%$ of all the invasive sea species in Europe. 


\section{Diseases}

The cage systems used in aquaculture harbor a series of conditions that lead to disease emergence and development. It is known that the antibiotics used in the open cage systems for the prevention of these diseases are released into the environment through fish feces and remain in water columns as sediments for long periods. The drugs used in disease treatment are fed to fish with feeds but only $1 \%$ of these drugs are absorbed by fish. In their study carried out in Greece, Rigos et al. (2004) [17] reported that $60-73 \%$ of an oxytetracyclineoriginated antibiotic fed to seabass was released into the environment through feces.

Although accurate and adequate use of medicines for the control of fish diseases has been reported to have minimal environmental impact, the number of the studies on the impact of antibiotic use on marine environment is not sufficient, albeit studies up to now have reported ecological risks.

Another important issue in fish diseases is that bacterial diseases are increasing and as well as causing drug resistance, the resultant drug resistance also affects human health. Although the studies on this issue are insufficient, its indirect threat to human health should not be ignored.

\section{Working Conditions}

In the aquaculture sector, poor living and working conditions of the employees, unfair salary, gender discrimination, child employment, limited access to health and education, occupational health and safety policies negatively affect production.

Most aquaculture farms are microenterprises and mainly employ individuals between the ages of 16 and 44. Most of the employers are men, and women are more actively working in inner-coast enterprises. In addition to occupational experience, the employees in this sector are expected to be literate and have computer skills [18]. Furthermore, Carneiro (2011) [19] reported that poor people have been alienated in the aquaculture sector because of their inability to invest in the sector.

Burbridge (2001) [20] reported that the aquaculture sector constituted $25 \%$ and $15 \%$ of the local employment in Spain and Finland, respectively, and their location at rural areas created their primary employment sources; they also reported that the biggest negative effect of aquaculture in these areas was that certain people had invested the biggest capital during the establishment of these farms and this may have the potential to cause inequality in income distribution and increase.

\section{Common Areas}

Aquaculture in seas has sea as a common denominator, which has many common uses. The shareholders of seas are tourism, environment, municipalities, nongovernmental organizations, fishers, local communities, etc. In the use of this common denominator, conflicts may rise among sea-coast-environment users. It is known that there is a particular conflict with the tourism sector, which is among the sectors that provide income and employment, and the aquaculture sector is, together with local communities and nongovernmental organizations, fighting against pollution and disease sources. It is also stated that managers of coastal settlements are acting in a similar manner and do not want these production areas in their regions.

\section{SOLUTION CRITERIA}

Briefly, when the solution recommendations for the environmental and social risks in offshore aquaculture are evaluated:

Ecosystem: Cage systems should be installed in areas determined within the framework of the law. Marine biodiversity, natural life and ecosystems functions must be preserved.

Water Management: In water management, the source must be fully utilized and by considering production requirements, human use, environmental requirements and impacts, public health and regional ecology should be taken into consideration. Feeds: Producers must provide raw material traceability/sustainability, and especially all the effects of raw materials that are alternatives to fishmeal and fish oil must be known.

Legal Procedure: Fish must be produced in accordance with national and international laws, and the enterprise must have all legal rights to the area in which it operates.

Chemical Use: Antibiotics, pesticides and other therapeutic drugs should be given and monitored by acknowledged experts in the field. All drugs must be used in a way that prevents their adverse effects on fish, human and environmental health. Alternative approaches to disease control should be developed.

Field Management: During their period of activity, the producers should inform the institutions and organizations about the production activities to improve transparency and coordination and to develop the area-based management plans. They must respect the rights of the local communities and encourage the contribution of the local communities and nongovernmental organizations to the area utilization and take their contribution into consideration.

Occupational Health and Safety: Public institutions, nongovernmental organizations and company employees should keep track of occupational health and safety protocols. Management must comply 
with local labor legislation and fundamental labor standards of the International Labor Office (ILO).

\section{RESULTS}

Sustainable use of water sources in aquaculture can only be achieved through rational planning and proper management strategies. For all sustainable aquaculture products, water at sufficient amounts and with high quality is needed, regardless of the differences in aquaculture systems. Nitrogen and phosphorus fractions, which are the main potential pollutants specific to aquaculture systems, enter into the environment either in dissolved form or particle form. In intensive aquaculture, feed and feces wastes have some adverse effects on sediments, whereas particle and dissolved elements have some adverse effects on water column. The main changes in water quality are characterized by the changes in nitrogen and phosphorus concentrations; the changes in sediment quality involve the variations in total nitrogen, total phosphorus, total carbon, organic matters and redox potential.

There seems to be an increase in certain problems related to the sector, which has been developing technologically and productively in recent years. The leading problem is the environmental pressure that aquaculture farming can create in the receiving environment. However, choosing an appropriate location and determining the business capacity based on environmental carrying capacity during the pre-production project phase is crucial in reducing the ecological effect and the risk posed by aquaculture. Within the context of aquaculture, in receiving environments and environment interaction, the issue of feed management is important in terms of reducing the effect of aquaculture enterprises on the environment. Feeding type, time and the nutrient content of feeds are highly important. The amount of pollutants due to enterprises and the load of nutrients can be determined by feeding ratios, feed utilization ratios, nitrogen and phosphorus contents of feeds or digestibility of feeds.

In conclusion, in order to ensure sustainable aquaculture-environment-society interaction:

-The future investments should be not only economic but also ecological.

-Feeds should be produced by considering feed costs of enterprises, they should be environmentally friendly and should be produced by considering the nutrient and energy requirements of the cultured organism.

-The phosphorus and nitrogen release due to feeds must be reduced.

-Nutrients with high digestibility should be preferred in feed rations and appropriate diets should be applied.

-In the installation of cage production systems, locations where water course is suitable should be chosen by considering cage sizes and depths.

-By the long-term planning of the sector, technologies to regulate the distribution of waste should be utilized, or attention should be paid to choose cages that allow rotation or relocation.

-Attention should be paid to stocking intensity and the waste amount due to stocking should be calculated.

-Polyculture systems should be improved.

-In aquaculture units, in case of fish deaths due to diseases, poisonings or a technical problem, these wastes should be removed by burial after liming or by incineration.

-By improving aquaculture methods, antibiotic use to combat diseases should be reduced with innovative fish health applications.

-In fish diseases, fish vaccination (preventive) methods should be preferred instead of antibiotics.

-Drug assimilation capacities of enterprises should be determined by using computer-based models, as it is the case in fish feeding or the monitoring of nutrient pollution.

-To reduce the antifouling chemical use, dirty equipment should be exposed to open-air, they should be washed with freshwater and the nets should be cleaned as frequently as possible.

-Since it is almost impossible to find an antifouling chemical that do not contain copper, the organisms that create biological pollution should be genetically studied and new nanotechnologies should be implemented.

-Aquaculture regulations on fish escapes from culture environments should be rearranged and by prioritizing the protection of natural stocks, environmental impact evaluations should be carried out.

-To prevent fish escapes from enterprises, equipment should be secured and the personnel should receive the necessary training.

-Enterprises must report fish escapes to relevant authorities.

-Enterprises should use triploid fish as much as possible to reduce the risk posed to the genetic pool by fish escapes.

-Aquaculture should be integrated with other sectors and contribute to a larger community and to other marine activities.

-The sector should collaborate with the local community and provide employment.

-The aquaculture sector should provide employment for women, especially in coastal enterprises, and contribute to their occupational development.

- Contribution should be made both to the promotion of the sector and to employment opportunities by providing full-time and part-time labor opportunities 


\section{REFERENCES}

[1]. TUIK, 2016. Fishery Statistics 2015. Turkish Statistical Institute, Ankara, Turkey. tuikapp. tuik. gov.tr/ medas/ ?kn=97 \&locale=tr (Date accessed: 10.01.2017).

[2]. Anonymous, 2014. Ministry of Environment and Urbanization, Regulation on Environmental Impact Assessment. Official Gazette November 24, 2014 Issue: 29186.

[3]. Jahncke, M.L., Schwarz. H.M., 2002. Public, Animal And Environmental Aquaculture Health İssues İn İndustrializaed Countries (edited by Michael L. Jahncke, E. Spencer Garrett, Alan Reilly, Roy E. Martin, Emille Cole) $205 \mathrm{pp}$.

[4]. Yıldırım, Ö., Korkut, A.Y., 2004. Effect of aquafeeds on the environment. Ege Journal of Fisheries and Aquatic Sci., 21 (1: 167-172.

[5]. Rast, W., Holland, M.M., 1988. Eutrophication of lakes and reservoirs: A framework for making management decisions. Ambio, 17(2):12.

[6]. Siddiqui, A.S., 2003. Waste water treatment technology in aquaculture. World Aquaculture, 49-51.

[7]. Gelineau, A., Corraze, G., Boujard, T., Larroquet L., Kaushık, S., 2001. Relation Between Dietary Lipid Level And Voluntary Feed İntake, Growth, Nutrient Gain, Lipid Deposition And Hepatic Lipogenesis İn Rainbow Trout, Reprod. Nutr. Dev. 41:487503.

[8]. Ferreira, C.S.G., Nunes, B.A., HenriquesAlmeida, J.M. de M., Guilhermino, L., 2007. Acute toxicity of oxytetracycline and florfenicol to the microalgae Tetraselmis chuii and to the crustacean Artemia parthenogenetica. Ecotoxicology and Environmental Safety, 67 (3): 452-458.

[9]. Igboeli, O.O., Fast, M. D., Heumannc, J., Burkaa J. F., 2012. Role of P-glycoprotein in emamectin benzoate (SLICE $\AA$ ) resistance in sea lice, Lepeophtheirus salmonis. Aquaculture $\quad 344-349$ : $\quad 40-47$. Doi:10.1016/j.aquaculture. 2012.03.026.

[10]. Veldhoen, N., Ikonomou, M.G., Buday, C., Jordan, J., Rehaume, V., Cabecinha, M., Dubetz, C., Chamberlain, J., Pittroff, S., Vallée, K., van Aggelen, G., Helbing, C.C., 2012. Biological effects of the anti-parasitic chemotherapeutant emamectin benzoate on a non-target crustacean, the spot prawn (Pandalus platyceros Brandt, 1851) under laboratory conditions. Aquatic Toxicology 108: 94-105.

[11]. Munari, C., Mistri, M., 2007. Effect of copper on the scope for growth of clams (Tapes philippinarum) from a farming area in the
Northern Adriatic Sea. Marine Environmental Research 64 (3): 347-357.

[12]. Mochida, K., Ito, K., Harino, H., Kakuno, A., Fujii, K., 2006. Acute toxicity of pyrithione antifouling biocides and joint toxicity with copper to red sea bream (Pagrus major) and toy shrimp (Heptacarpus futilirostris). Environmental Toxicology and Chemistry 25 (11): 3058-3064.

[13]. Cid, A., Herrero, C., Torres, E., Abalde, J., 1995. Copper toxicity on the marine microalga Phaeodactylum tricornutum: effects on photosynthesis and related parameters. Aquatic Toxicology 31 (2): 165174.

[14]. Franklin, N.M., Stauber, J.L., Lim, R.P., 2001. Development of flow cytometry-based algal bioassays for assessing toxicity of copper in natural waters. Environmental Toxicology and Chemistry 20 (1): 160-170.

[15]. Dean, R.J., Shimmield, T.M., Black, K.D., 2007. Copper, zinc and cadmium in marine cage fish farm sediments: an extensive survey. Environmental Pollution, 145 (1): 8495.

[16]. Katsanevakis, S., Zenetos, A., Belchior, C., Cardoso, A.C., 2013. Invading European Seas: Assessing pathways of introduction of marine aliens. Ocean \& Coastal Management 76: 64-74.

[17]. Rigos, G., Nengas, I., Alexis, M., Troisi, G.M. (2004) Potential drug (oxytetracycline and oxolinic acid) pollution from Mediterranean sparid fish farms. Aquatic Toxicology 69 (3): 281-288.

[18]. Lantra, 2006. Aquaculture Industry Occupational and Functional Map. (Available from www.lantra.co.uk).

[19]. Carneiro, G., 2011. Marine management for human development: a review of two decades of scholarly evidence. Marine Policy, 35, pp: 351-362.

[20]. Burbridge, P. Hendrick, V, Roth, E. and Rosenthal, H., 2001. Social and economic policy issues relevant to marine aquaculture. J. Appl. Ichthyol. 17, pp: 194-206. 